\title{
ON SCHUR $m$-POWER CONVEXITY FOR RATIOS OF SOME MEANS
}

\author{
Hong-PIng Yin, HuAn-NAn Shi AND FEng QI
}

Abstract. In the paper, the authors discuss the Schur $m$-power convexity on $(0, \infty) \times(0, \infty)$ for ratios of some famous means, such as the arithmetic, geometric, harmonic, root-square means, and the like, and obtain some inequalities related to ratios of means.

Mathematics subject classification (2010): Primary 26B25; Secondary 26E60, 26D20.

Keywords and phrases: Schur $m$-power convexity, quotient, mean, arithmetic mean, geometric mean, harmonic mean.

\section{REFERENCES}

[1] Y.-M. ChU, X.-M. ZHANG, AND G.-D. WANG, The Schur geometrical convexity of the extended mean values, J. Convex Anal. 15 (2008), no. 4, 707-718.

[2] A. W. Marshall, I. Olkin, and B. C. Arnold, Inequalities: Theory of Majorization and its Applications, 2rd Ed., Springer Verlag, New York-Dordrecht-Heidelberg-London, 2011; Available online at http://dx.doi.org/10.1007/978-0-387-68276-1.

[3] F. QI, Integral representations and properties of Stirling numbers of the first kind, J. Number Theory 133 (2013), no. 7, 2307-2319; Available online at http://dx.doi.org/10.1016/j.jnt. 2012.12 .015$.

[4] H.-N. SHI, J. ZHANG, AND D.-M. Li, Schur-geometric convexity for differences of means, Appl. Math. E-Notes 10 (2010), 275-284.

[5] I. J. TANEJA, Nested inequalities among divergence measures, Appl. Math. Inf. Sci. 7 (2013), no. 1, 49-72; Available online at http://dx.doi.org/10.12785/amis/070106.

[6] I. J. TANEJA, On a difference of Jensen inequality and its applications to mean divergence measures, RGMIA Res. Rep. Coll. 7 (2004), no. 4, Art. 16; Available online at http://rgmia.org/v7n4.php.

[7] I. J. TANEJA, Refinement of inequalities among means, J. Comb. Inf. Syst. Sci. 31 (2006), no. 1-4, 343-364.

[8] I. J. TANEJA, Sequence of inequalities among differences of Gini means and divergence measures, J. Appl. Math. Statist. Inform. 8 (2012), no. 2, 49-65; Available online at http://dx.doi.org/ 10. 2478/v10294-012-0014-2.

[9] I. J. TANEJA, Seven means, generalized triangular discrimination, and generating divergence measures, Information (2013) no. 4, 198-239; Available online at http://dx.doi.org/10.3390/ info4020198.

[10] B.-Y. WAng, Foundations of Majorization Inequalities, Beijing Normal Univ. Press, Beijing, China, 1990. (Chinese)

[11] Y. WU AND F. QI, Schur-harmonic convexity for differences of some means, Analysis (Munich) 32 (2012), no. 4, 263-270; Available online at http://dx.doi.org/10.1524/anly.2012.1171.

[12] Y. WU, F. QI, AND H.-N. SHI, Schur-harmonic convexity for differences of some special means in two variables, J. Math. Inequal. 8, 2 (2014), 321-330; Available online at http://dx.doi.org/10.7153/jmi-08-23.

[13] W.-F. XIA AND Y.-M. CHU, Schur-convexity for a class of symmetric functions and its applications, J. Inequal. Appl. 2009 (2009), Article ID 493759, 15 pages; Available online at http://dx.doi.org/10.1155/2009/493759.

[14] Z.-H. YANG, Schur power convexity of Stolarsky means, Publ. Math. Debrecen 80 (2012), no. 1-2, 43-66; Available online at http://dx.doi.org/10.5486/PMD . 2012.4812. 